\title{
EUROSON 2018 Poznan, Poland - a short overview
}

On the occasion of the $30^{\text {th }}$ EUROSON Congress in Poznan Poland the EFSUMB Past Presidents were invited to share in a history of ultrasound session. Not all were able to be present and it is with sadness that we report the recent death of Francis Weill who was not only EFSUMB President in 1984 - 1987 but also WFUMB President in 1988. We enjoyed presentations from PP 11 Harald Lutz on the History of US in Germany East and West, PP 10 Sturla Eik-Nes on the Scandinavian Perspective, PP 9 Luigi Bolondi who talked about 3 EFSUMB Presidents and 2 EUROSONs all from Bologna! PP 6 David Evans gave a very short history of the Doppler effect and PP 4 Christian Nolsoe talked about the Interventional Ultrasound Pioneers in Europe. PP 2 Christoph F Dietrich introduced the session with PP1 Odd Helge Gllja and plans are afoot to preserve this history.

THe EUROSON Congress in Poznan, Poland was a great success of EFSUMB and Polish colleagues, especially Dr. Wojciech Kosiak, Polish and Congress Joint President. One of the most prominent features of the meeting was a young and active participant profile. Among them was a Turkish young man Hadi Ozer (aged 91), the founder of the

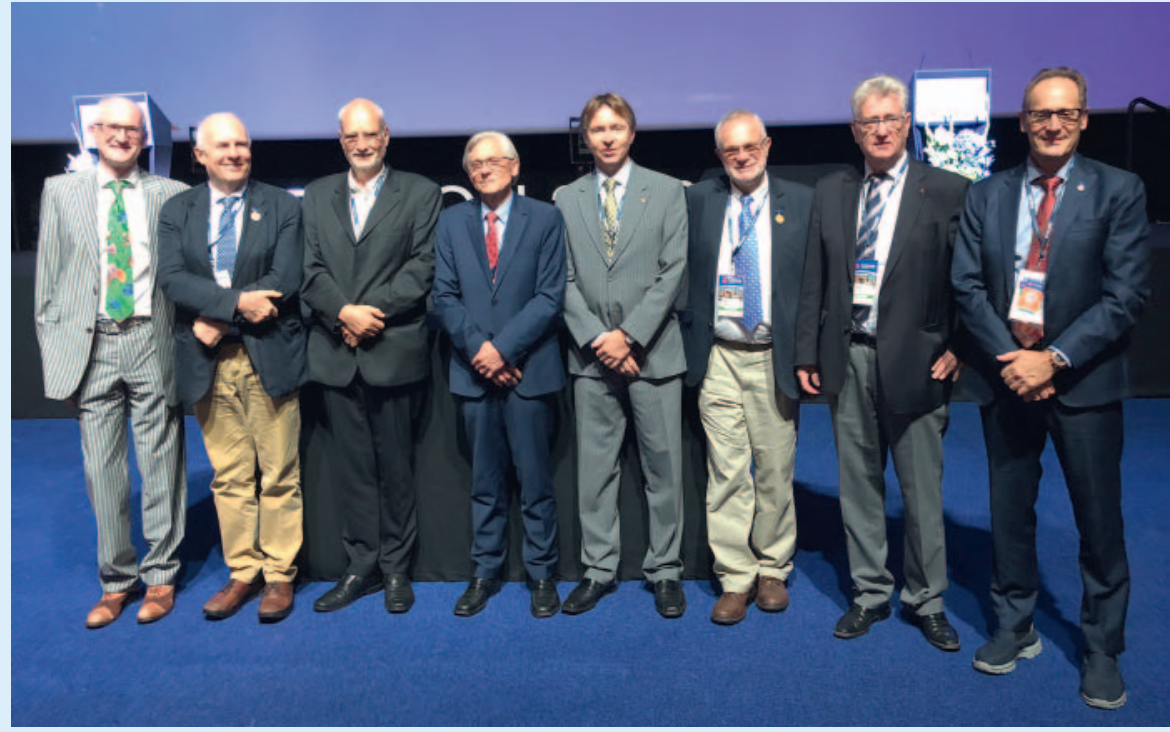

Profs Dietrich, Bolondi, Jäger, Eik-Nes, Gilja, Evans, Lutz and Nolsoe (I to r).

Turkish Ultrasound Society, who lectured on the development of ultrasound in Turkey and the USA in a special history session.

He had worked with some of the pioneers of ultrasound, during his fellowship in Philadelphia, in 1963, almost 55 years ago. The day he first used ultrasound was unforget- table not only because of this event but by the coincidence of Kennedy assasination.

Later, in 1970, he worked together with Dr. Edward H. Smith, as an assistant Prof. of Radiology, in Harvard and with Dr. Hans Henrik Holm from Herlev Hospital, Copenhagen, Denmark. 


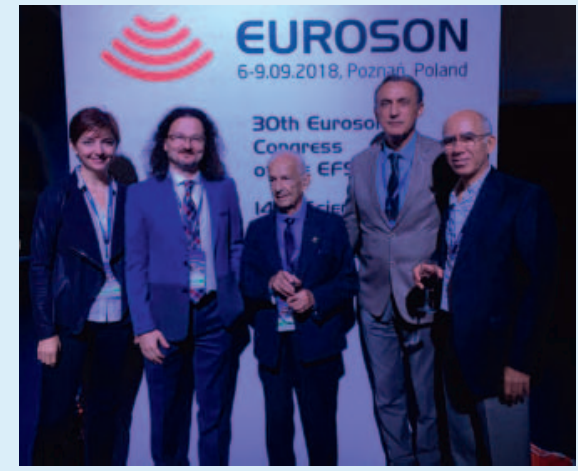

Prof. Hadi Özer, founder of The Turkish US Society, is together with the current (Prof. Mustafa Seçil-on his right), and the past presidents (Prof. Adnan Kabaalioğlu and Prof. S. Süreyya Özbek-on his left side) of the Society. Prof. Suna Ö. Oktar (on the far left) is also a member of the Executive Committee of TUDS.

He founded theTurkish US Society in 1985 , with his colleagues. The Society has long a tradition of a maximum of 4 years of Presidency.

The EFSUMB Young Investigator Session was an exciting competition with diverse presentations.

The EFSUMB Best Published Paper (500 euro) was won by Ben Stendberg (UK) for the paper published in Eur Radiol (2017) 27:4525 - 4531 entitled "The prevalence and significance of renal perfusion defects in early kidney transplants quantified using 3 D contrast enhanced ultrasound (CEUS)."

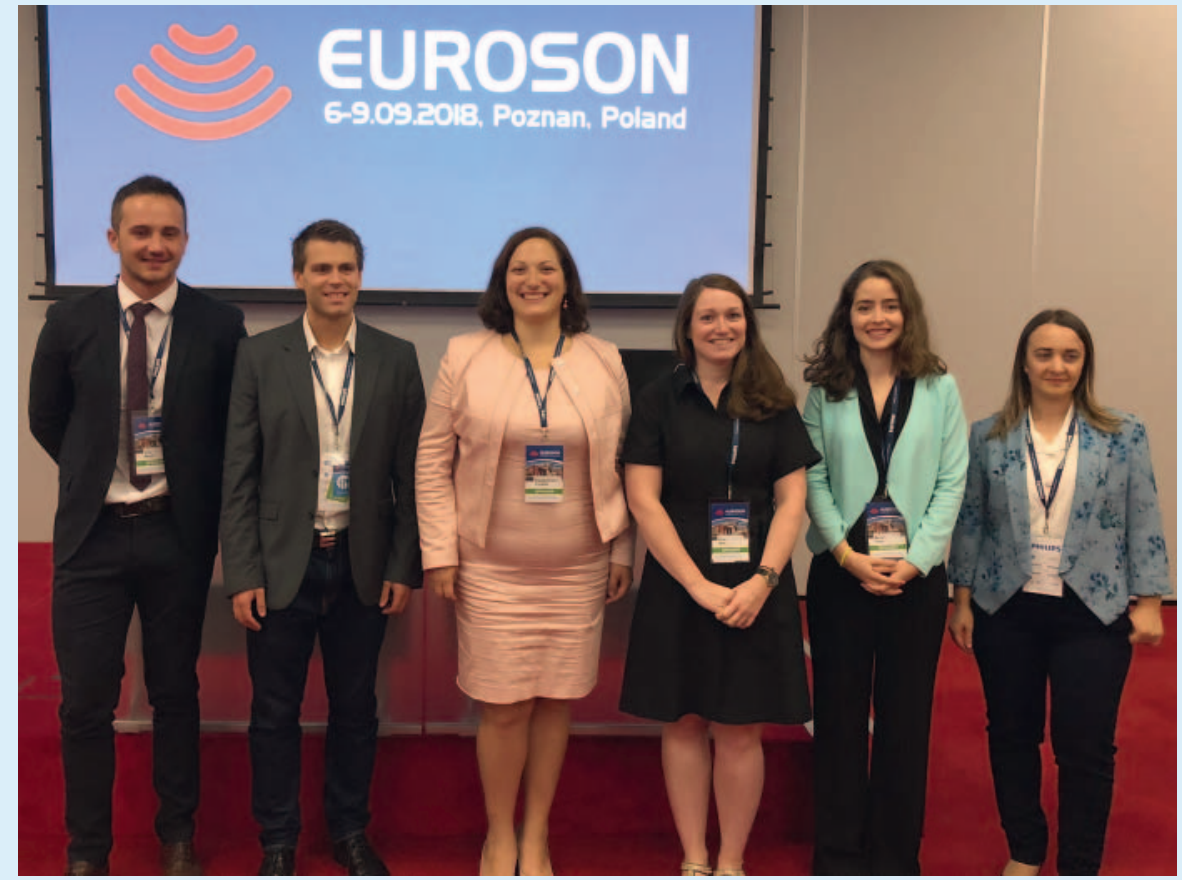

(from left to right) Romania, Norway, Italy, Netherlands, UK and Turkey (the Polish student not photographed). The winner (with 3000 euro in prize money) in this close competition was Marcia Costa (UK) for her talk on 'Combined focused ultrasound and radiotherapy for the treatment of hypoxic tumours, using photoacoustic imaging as planning tool.'

The Walter Kreinitz 500 euro prize for the best oncological abstract submitted to the EUROSON congress was won by Shaoshan Tang (China) with the abstract "Value of Contrast-enhanced Ultrasound in Diagnosis and Differential Diagnosis of Apophysis Lesions of the Gallbladder $>1 \mathrm{~cm}$ "
Congratulations to Prof Wojciech Kosiak and his team (and of course Dr Mateusz Kosiak for his entertaining review of medical dramas) for the vision and enthusiasm to create a memorable congress with 1400 participants from around the world. Visit the efsumb.org website to see more images. 